\title{
Formative evaluation to benchmark and improve climate-based decision support for graziers in Western Queensland
}

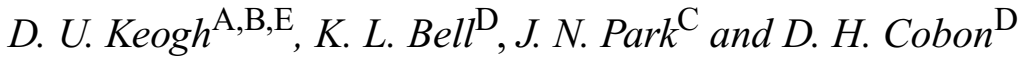 \\ ${ }^{A}$ Queensland Centre for Climate Applications, Department of Natural Resources, Mines and Energy, \\ 203 Tor Street, Toowoomba, Qld 4350, Australia. \\ ${ }^{B}$ Present address: Queensland Transport, 230 Brunswick Street, Fortitude Valley, Qld 4006, Australia. \\ ${ }^{\mathrm{C}}$ Queensland Centre for Climate Applications, Department of Primary Industries and Fisheries, \\ Landsborough Highway, PO Box 519, Longreach, Qld 4730, Australia. \\ ${ }^{\mathrm{D}}$ Queensland Centre for Climate Applications, Queensland Department of Primary Industries and Fisheries, \\ 203 Tor Street, Toowoomba, Qld, 4350, Australia. \\ ${ }^{\mathrm{E}}$ Author for correspondence; e-mail: diane.u.keogh@transport.qld.gov.au
}

\begin{abstract}
Researchers developing climate-based forecasts, workshops, software tools and information to aid grazier decisions undertook an evaluation study to enhance planning and benchmark impact. One hundred graziers in Western Queensland were randomly selected from 7 shires and surveyed by mail and telephone ( 43 respondents) to explore levels of knowledge and use of climate information, practices and information needs. We found $36 \%$ of respondents apply the Southern Oscillation Index to property decisions but $92 \%$ were unaware El Niño Southern Oscillation's predictive signal in the region is greater for pasture growth than rainfall, suggesting they may not recognise the potential of pasture growth forecasts. Almost $75 \%$ of graziers consider they are conservative or risk averse in their attitude to managing their enterprise. Mail respondents $(n=20)$ if given a $68 \%$, on average, probability of exceeding median rainfall forecast may change a decision; almost two-thirds vary stocking rate based on forage available, last year's pasture growth or the Southern Oscillation Index; the balance maintain a constant stocking rate strategy; $90 \%$ have access to a computer; $75 \%$ to the internet and $95 \%$ have a fax. This paper presents findings of the study and draws comparisons with a similar study of 174 irrigators in the Northern Murray-Darling Basin (Aust. J. Exp. Ag. 44, 247-257). New insights and information gained are helping the team better understand client needs and plan, design and extend tools and information tailored to grazier knowledge, practice, information needs and preferences. Results have also provided a benchmark against which to measure project impact and have influenced the team to make important changes to their project planning, activities and methods for transferring technology tailored to grazier preferences.
\end{abstract}

Additional keywords: benchmarking, client focus, continuous improvement, extension planning, seasonal climate forecasts.

\section{Introduction}

How do we know we have been successful?

A considerable proportion of agricultural research and extension is done without measuring whom uses the knowledge or technology extended, how or what costs or benefits resulted. A review of program evaluation in agricultural extension in Australia found few publications on results of evaluations (Dart et al. 1998). It has even been suggested evaluating research fields require a new kind of social accountability and responsibility that may not be forthcoming from scientific communities (Luukkonen-Gronow 1987). Lynch et al. (2000) suggest criteria used to evaluate the success of intelligent agricultural decision support systems are often stated in technical, and not farmer use and impact terms. Cox (1996) considers underlying skills in systems analysis have not been exploited adequately in development of decision support technologies, and opportunities to learn from sometimes beneficial and significant side-effects of development have not been taken or progressed. So what does this suggest?

Evaluation activities can provide formal frameworks and approaches for analysing and learning about farmer perspectives and decision information needs. Evaluation data can prompt new ideas for agricultural professionals, which can lead to improved and more relevant planning through a greater understanding of client needs and preferences. Studies can be designed to enhance a program's or project's success and/or gather evidence of impact. Research and extension professionals need to evaluate and examine the relevance and adoption of their work (Pollard 
1992; Clewett et al. 2000). Evaluation is an investigative technique that can test and explore these questions; using a structured questionnaire is one method of evaluating.

Are evaluation findings useful for planning and decision making? Can evaluation enhance knowledge transfer or help assess impact? This paper presents examples of how results of a formative evaluation study influenced and led to changes in a grazier project's planning and activities and compares results with a similar study of irrigators. Results of the grazier evaluation helped tailor development of decision tools, information, workshops, communication and extension strategies to the knowledge, needs, practices and preferences of the intended audience. The evaluation also provided benchmarks, against which research and extension impact may be measured by comparing results with an 'after' study planned at the conclusion of this project. The studies referred to in this paper were of graziers in Western Queensland and regulated irrigators in the New South Wales (NSW) and Queensland sections of the Northern Murray-Darling Basin (Keogh et al. 2000a, 2000b, 2004).

\section{Climate-based information to aid property decisions}

The term 'Southern Oscillation Index' (SOI) has been used in our language since the early 1980s and seasonal climate forecasts, based on El Niño Southern Oscillation (ENSO), have been available during the last decade (McBride and Nicholls 1983; Clewett et al. 1994, 1999; Cane 2000). The Southern Oscillation is 'a see-saw of atmospheric pressure anomalies between the Indonesian region and the eastern tropical Pacific Ocean' and it 'explains as much as $40 \%$ of the variance in eastern Australian rainfall' (Partridge 1994: p. 12). The Troup SOI (Troup 1965) is defined as the standardized difference between the sea level pressures at Tahiti and Darwin, multiplied by a factor of 10 . ENSO is a combination term for El Niño-Southern Oscillation. 'El Niño' is now used more widely to refer to this abnormal warming of the ocean and the resulting effects on weather. 'El Niño' is often coupled with 'Southern Oscillation' as the acronym ENSO (Partridge 1994: p. 13).

Climate variability is a significant challenge for graziers in northern Australia and in central and north west Queensland, summer dominant rainfall is usually followed by a long and variable dry season of between 6 and 8 months (Park et al. 2001). ENSO impacts on seasonal rainfall and pasture growth in Western Queensland; however, its greatest impact is on pasture growth and pasture growth forecasts have the potential to be more useful for graziers than rainfall forecasts (Cobon 1999; Park et al. 2001). Communicating probabilistic forecasts and climate-based information to non-technical audiences can be challenging. Impediments may exist to optimal use of forecasts (Nicholls 2000), including difficulty with interpretation and limited access to expertise (Changnon et al. 1995; Austen et al. 2002).
Developing an understanding of target audience knowledge, practices, needs and preferences can aid knowledge transfer and contribute to improving client understanding of climate terms, tools, information and application to decisions.

\section{Formative evaluation to aid planning and measure impact}

A project team of research and extension specialists, delivering climate-based forecasts, tools, information, and training to aid sustainable grazier decision making in Western Queensland, undertook a formative evaluation study to guide planning and benchmark impact. A similar study of irrigators in the Northern Murray-Darling Basin was also undertaken by water resource climate specialists (Keogh et al. 2000a, 2000b, 2004). Little data was available on levels of grazier or irrigator understanding and use of climate information, what information they needed or how they prefer to access it, nor was benchmark data available in the regions on these attributes against which to make comparisons.

There are almost 60 different approaches for conducting evaluation studies (Worthen et al. 1997). Formative evaluation can help team members develop new ideas and approaches or provide judgements that may improve a program; it generally reports to, rather than on, a program or project (Posavac and Carey 1997; Dart et al. 1998). We adopted this approach and also used formative evaluation to establish benchmarks of grazier and irrigator knowledge and practice, to aid assessment and measurement of project impact and effectiveness on completion.

The grazier study provided valuable insights into: gaps in grazier knowledge and understanding of climate; how the SOI is applied to decisions; factors important in decision-making; information needs and preferences; management practices, including how graziers decide stocking rates; record keeping practices; and use of technology, such as computers, the internet and fax. New scientific knowledge that is poorly communicated, unable to reach a target audience or unable to be easily interpreted is unlikely to be useful. The implications of this study are that formative evaluation is aiding knowledge transfer and benchmarking, to help measure project impact and effectiveness. Effort needs to be expended to understand the requirements, practice, knowledge and preferences of intended beneficiaries of research.

\section{Methods}

The grazier study was designed for the Department of Primary Industries and Fisheries, Queensland Centre for Climate Applications (QCCA) project 'Sustainable Grazing — balancing resources and profit in western Queensland' funded by the Natural Heritage Trust (Project No. 992606). It was based on a similar study, by Department of Natural Resources, Mines and Energy/QCCA, of 174 regulated irrigators in the Border Rivers, Gwydir, Namoi and Upper Condamine catchments of the Northern Murray-Darling Basin (Keogh et al. 2000a, 2000b, 2004).

The main hypotheses of the irrigator study were: (i) irrigators do not consult when making cropping area decisions; (ii) irrigators do not have 
sufficient knowledge of climate phenomena to use in planning; and (iii) irrigators do not consider water availability forecasts useful in decision-making. In August 1999, an anonymous mail questionnaire, comprising 128 questions and pre-tested with 22 farmers across the survey region, was sent to all regulated irrigators involved in agricultural production in the survey region. One hundred and seventy-four usable responses ( $18.7 \%$ response rate) were received: 74 cotton and 100 non-cotton growers. Forty-one irrigators expressed interest in participating in the focus group to advise the researchers; 108 requested that a copy of survey results be forwarded to them. The study sought to ensure research outputs matched the requirements of the intended audience and facilitated formation of a focus group of respondents and their advisors. This focus group is cooperating with researchers to assess findings and suggest improvements to the project's set of decision support tools under development. The study found: there was not enough evidence to accept that irrigators do not consult on decisions; irrigators' general understanding of climate signals and terms was quite good; and there was sufficient evidence to prove that irrigators do consider water availability forecasts useful in decision making. Valuable information was gained on how irrigators make water management and cropping area decisions, as well as levels of understanding and use of climate information. Results are helping improve product utility, project planning and decision-making and devise effective dissemination channels, formats and extension strategies to maximise knowledge transfer (Keogh et al. 2004).

\section{Evaluation objectives and approach}

The goals of the grazier study were to: (i) benchmark grazier understanding and use of climate information; (ii) understand how they make stocking rate and management decisions; (iii) examine the extent to which property records, computers and software are used; (iv) identify tools and information sources used to aid decisions; and (iv) determine preferred methods for accessing information. A formative evaluation approach was adopted and a structured questionnaire used to collect data. Questions were designed with decision-making specifically in mind (Luukkonen-Gronow 1987), to explore evaluation objectives and to contribute to achievement of project goals. Two methods were used to assess grazier understanding of climate phenomena and terms commonly used in climate science: (i) 5 climate test questions (Table 1, Section C; Table 3) and (ii) self-rating their currrent knowledge or skill in relation to 15 climate

\section{Table 1. Sections of the grazier survey}

\begin{tabular}{ll}
\hline Section & Questions related to: \\
\hline Section A & $\begin{array}{c}\text { Property characteristics such as area, gross annual } \\
\text { turnover, stocking rates, rainfall and property } \\
\text { record-keeping practices }\end{array}$ \\
Section B & $\begin{array}{c}\text { Grazier knowledge of the climate system; how they use } \\
\text { the SOI in property decisions } \\
\text { Grazier understanding of sea surface temperatures, SOI, } \\
\text { Section C }\end{array}$ \\
Section D & $\begin{array}{c}\text { Factors important in deciding stocking rate; who graziers } \\
\text { consult; how they decide stock numbers; management } \\
\text { methods; and strategies to manage numbers }\end{array}$ \\
Section E & $\begin{array}{c}\text { Whether decision tools would be useful to aid climate, } \\
\text { pasture growth, stock number decisions; how graziers } \\
\text { prefer to access this information; access to computers, } \\
\text { internet and fax; and whether computer packages are } \\
\text { used to aid property management } \\
\text { Personal contact details: name, postal address, telephone, } \\
\text { fax, email, mobile }\end{array}$ \\
\hline
\end{tabular}

phenomena and terms (Table 1, Section B; Table 4). An overview of survey process is shown in Figure 1. Unlike the irrigator study, the identity of respondents in the grazier study is known.

Survey region and sample selection

The survey area consisted of 7 shires in Western Queensland, Aramac, Blackall, Ilfracombe, Longreach, McKinlay, Richmond and Winton (Fig. 2). In an attempt to obtain a representative and random selection of graziers, a stratified sampling design, based on shire, was used and $12 \%$ of each shire's population sampled. Shire was chosen as the stratification characteristic as the local government listing of all properties in the region provided only owner/manager name and address details. One hundred graziers were selected from the listing of 866.

\section{Survey instrument and data collection}

A structured survey comprising 121 questions, arranged in 6 sections, was designed to explore the goals of the evaluation (Table 1) and questions were based on a survey of all 931 regulated irrigators in the Northern Murray-Darling Basin (Keogh et al. 2000a, 2000b, 2004).

The grazier survey was pre-tested with QCCA staff and local colleagues. The final version was mailed to 100 graziers in the region on 10 November 2000, requesting responses by 1 December 2000. Data was collected using 2 methods: mail and telephone (Martin et al. 1999). Initial response by mail was $20 \%$ and a telephone follow-up of 71 of the 80 non-respondents in March-April 2001 boosted response rate by a further $23 \%$. Thirty-two percent of the non-respondent population contacted agreed to participate in the telephone survey, $27 \%$ refused and the balance could not be contacted. Telephone respondents were asked 48 of the 121 questions on the mail survey. All respondents were sent a complimentary map of 100 years of monthly Australian rainfall information and they were entered into a draw to win a copy of the Australian Rainman computer software program. A flowchart depicting survey method is shown in Figure 3.

\section{Response rate}

Overall sample response rate was $43 \%$, varying between shires from $17 \%$ in Ilfracombe to $63 \%$ in McKinlay (Table 2). All non-respondents were contacted, however, due to time and resource restrictions, the decision was taken not to continue random sampling from the population until 100 responses were received. The 43 respondents represent $5 \%$ of the total population on the grazier listing and they collectively manage $\sim 6 \%$ of the total land area in the region, including stock routes and towns (Park et al. 2001). When considering return rates of $6-65 \%$ from other mail-out surveys to farmers, that used a variety of methods for selecting their populations (Bayley et al. 1994; Keogh et al. 2000a, 2000b, 2004; Hayman and Alston 1999; Paull and Hall 1999), the project team considered a $43 \%$ sample response rate sufficient for the purpose of this study.

It is recognised that, as there were only 43 respondents out of a random selection of 100 , there could be possible bias in the survey results. Some of the sample did not respond because they were no longer in the industry, while others may have chosen not to respond due to disinterest in climate information or filling out surveys. There is a chance that the graziers in this latter group may be correlated with factors such as income, management skill and climate knowledge, causing an unknown bias in our results; however, we are unable to quantify this due to lack of information about each of these factors in relation to population. It is difficult to compare non-respondents with respondents, however, we found no bias in terms of property size, with the estimated average size of rural holdings of our survey respondents similar to that recorded by the Australian Bureau of Statistics. According to the Australian Bureau of Statistics (2000), the size of rural holdings for the 9 shires (Aramac, Barcaldine, Blackall, Flinders, Ilfracombe, Longreach, McKinlay, Richmond, Winton) was 24956403 ha and the number of rural holdings for those shires was 881 . This 
indicates an average size of holding of 28327 ha, compared with our grazier respondent average of 28270 ha.

\section{Variables measured and statistical tests conducted}

Statistical analyses tools. Chi-square analyses, using data from contingency tables, were used to compare cross-tabulated count data to test for independency. For example, assessing the independency of yes/no answers across mail or telephone respondents or a cross tabulation across 2 questions. For $2 \times 2$ tables, the Yates adjustment was used (Snedecor and Cochran 1980). It is recommended in statistical texts (e.g. Snedecor and Cochran 1980) that expected values in the contingency tables do not go below 1 and no more than $20 \%$ go below 5. These recommendations were checked for each analysis and, if necessary, categories grouped or analysis not performed.

A 1-way analysis of variance was used to compare groups where the responses were assumed continuous, normally distributed and the variances similar across groups. If an analysis was significant, the least significant difference procedure (Snedecor and Cochran 1980) was used to determine which levels of a factor were different. The ratings from 1 to 10 were assumed appropriate for analysis of variance. The property size responses were $\log _{\mathrm{e}}$ transformed, due to the skewed distribution. All tests used a 5\% level of significance.
Gross annual turnover was grouped into ' $<\$ 150000$ ' and ' $>\$ 150000$ '. Stocking rate categories were calculated to adult dry sheep equivalents (dse), using the conversion rate of 7 dry sheep equivalents to 1 adult cattle equivalent (ae). Three groups were formed: $<0.55 \mathrm{dse} / \mathrm{ha} ; 0.55-0.8 \mathrm{dse} / \mathrm{ha}$; and $>0.8 \mathrm{dse} / \mathrm{ha}$ ). North Region is represented by McKinlay, Richmond and Winton shires $(n=23)$ and South Region by Aramac, Blackall, Ilfracombe and Longreach shires $(n=20)$.

Statistical tests performed. Firstly, statistical tests were performed on the results from mail respondents and telephone respondents. Tests were performed on a question-by-question basis, except for self-rating current knowledge or skill (Section B of the survey), as mail respondents used a 10-point scale and telephone respondents a 4-point scale. Secondly, statistical tests were performed on 6 factors (gross annual turnover, use of the SOI in decision making, tendency to avoid or take risks in management of grazing enterprise, level of computer skill, region and stocking rate) by:

(i) cross tabulating the 6 factors, 2 at a time;

(ii) comparing how graziers rated their understanding of 15 climate phenomena and property size across the levels of the 6 factors ( 1 factor at a time); and

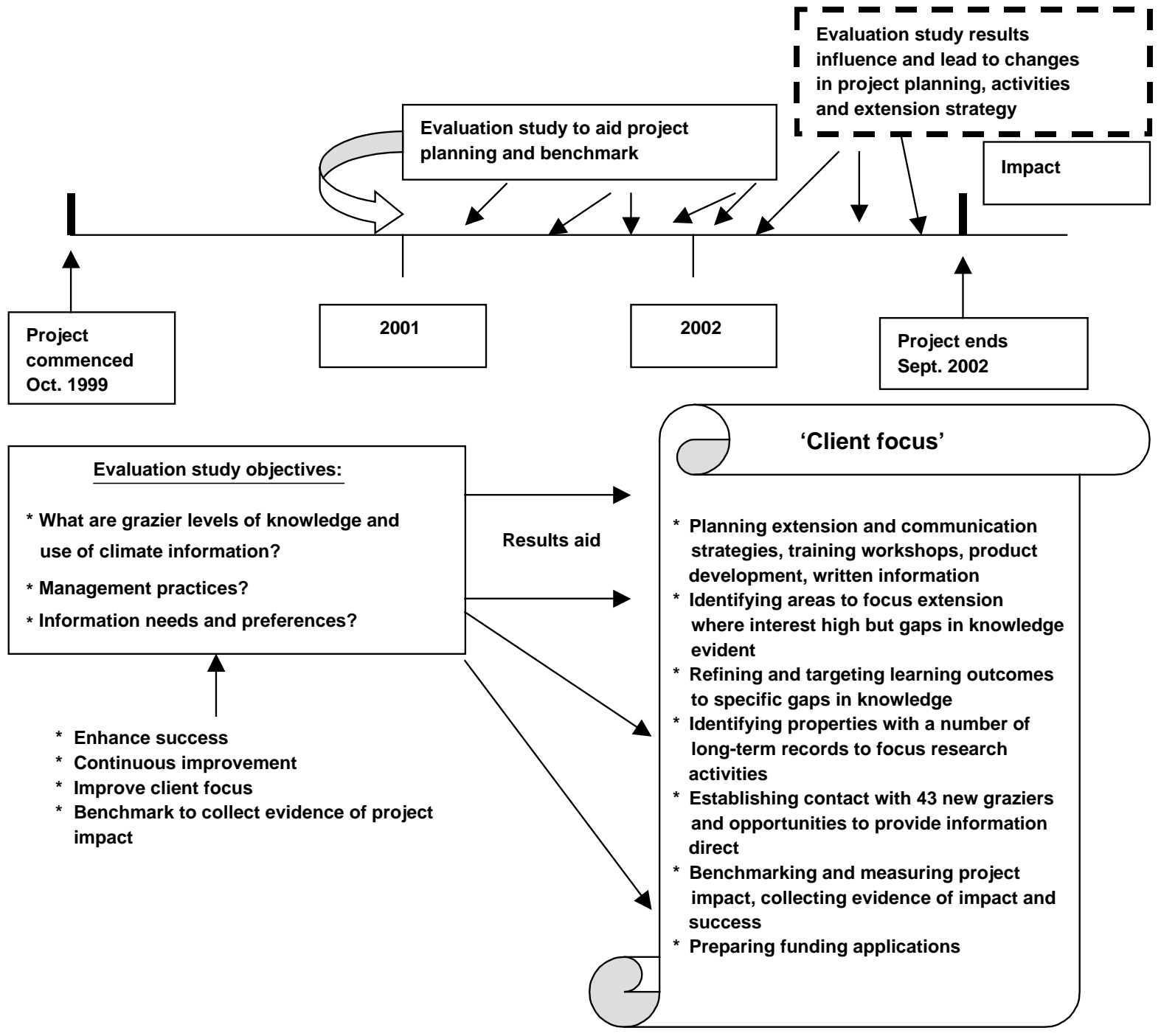

Figure 1. Formative evaluation study for sustainable grazing and climate information project in Western Queensland. 
(iii) comparing the correct answers to the 5 climate knowledge questions in (Section $\mathrm{C}$ of the survey) across the factors ( 1 factor at a time).

Finally, statistical tests were performed on responses from the similar survey of regulated irrigators in 1999, using questions that were common or similar between both surveys.

\section{Results}

Study objectives were to enhance project planning and success by gaining a better understanding of the target audience and adapting findings to project activities. The main findings are presented in text and tabular formats (Tables 3-7). The tables provide a snapshot of grazier knowledge, practice, information needs and preferences. Trends in use of the SOI and climate knowledge are examined. Study results are compared with the 1999 regulated irrigator survey in the Northern Murray-Darling Basin (Keogh et al. 2000a, 2000b, 2004).

In Section C of the survey, the mail respondents correctly answered that SOI in an El Niño year was negative, significantly $(P=0.004)$ more often $(94.4 \%)$ than the telephone respondents $(47.8 \%)$. Telephone respondents, however, correctly answered the difficult and highly technical question that 'In a La Niña event, sea surface temperature (SSTs) around the equator in the eastern Pacific
Ocean are colder than average' more often (60.9\%) than the mail respondents $(26.3 \%)$, at a statistical probability level of 0.054 which is close to the $5 \%$ level of significance.

La Niña events are generally associated with warming of the ocean, however, in the eastern Pacific near the equator the phenomenon is cooling. The high number of telephone respondents correctly answering this question may be due to wording of the question and not understanding of the phenomena. The question was particularly difficult and required a thorough understanding of the ENSO phenomena.

Statistical tests, performed on 24 questions, revealed no difference between the mail and telephone groups of respondents with respect to the following questions:

(i) property size and gross annual turnover;

(ii) how graziers rated their knowledge/skill in sourcing weather and climate information and understanding of 14 climate phenomenon and terms such as SOI, SOI phases and median rainfall;

(iii) whether graziers use the SOI in decision making and types of decisions they apply the SOI to;

(iv) the percentage of correct answers to 3 of the climate test questions relating to sea surface temperatures, SOI phases and ENSO; and
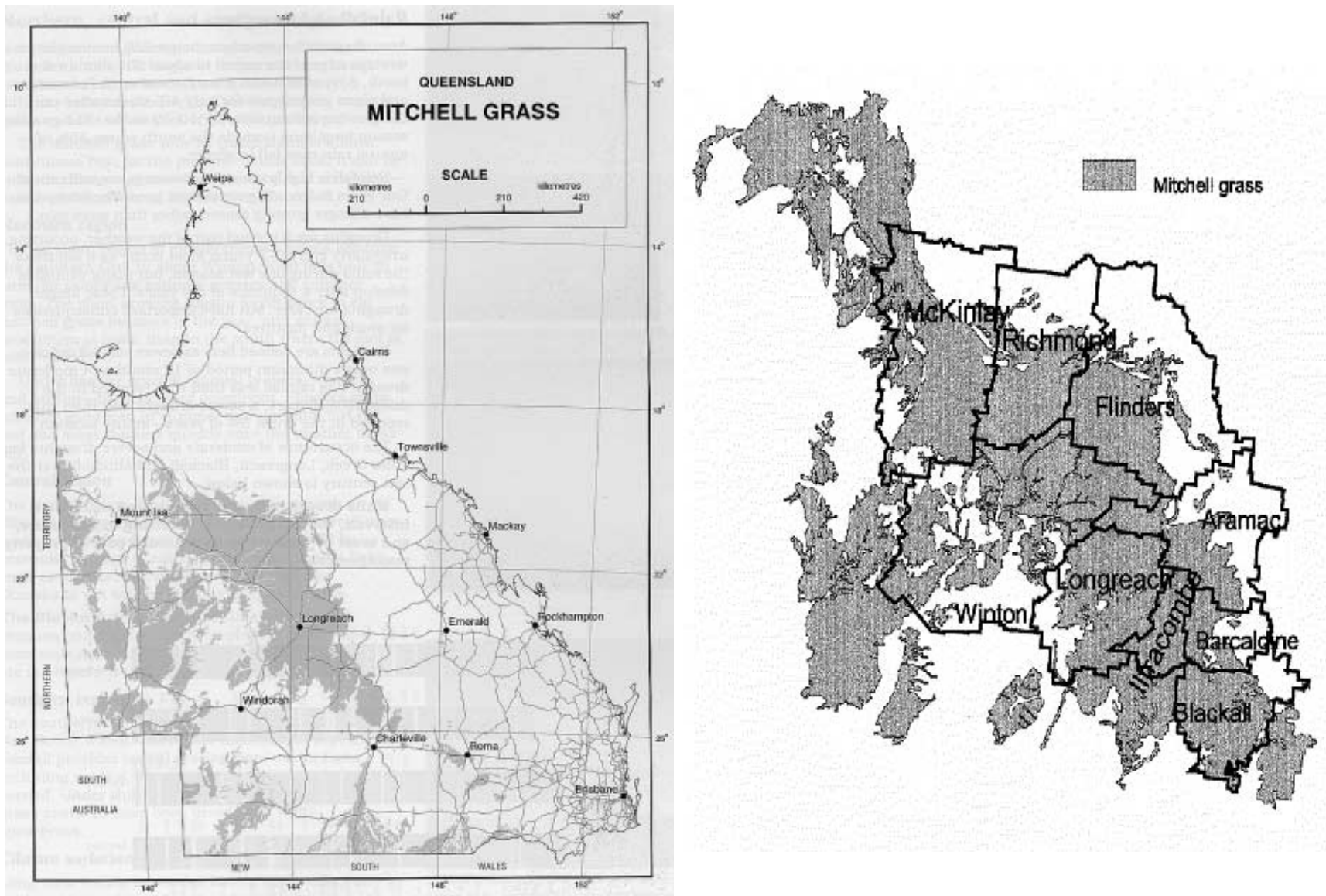

Figure 2. Survey region in Western Queensland. 
(v) whether they consider they take or avoid risks in managing their grazing enterprise. Mail respondents had a choice of 2 responses ('avoid risks' or 'take risks') and telephone respondents had a third option ('conservative'). In combining responses, 'conservative' answers were grouped with 'avoid risks'.
All other tests showed non-significant differences between the mail and telephone respondents' answers.

Questions from mail respondents in the grazier survey

We found no significant difference between what mail respondents consider to be safe carrying capacities for their properties (i.e. the number of stock they think they could

August 2000

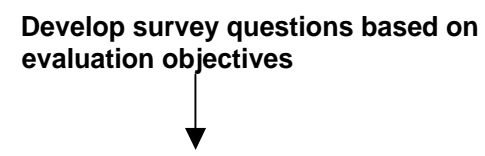

Pre-test questionnaire with local colleagues

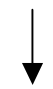

Redraft questionnaire incorporating suggested changes

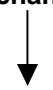

Early November 2000

Media release prior to mailing questionnaires, alerting survey on its way

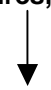

10 November 2000

Questionnaires mailed to 100 graziers randomly selected from 7
shires with request to respond within
2 weeks, by 1 December 2000 graziers randomly selected from 7
shires with request to respond within
2 weeks, by 1 December 2000 graziers randomly selected from 7
shires with request to respond within
2 weeks, by 1 December 2000

1 December 2000
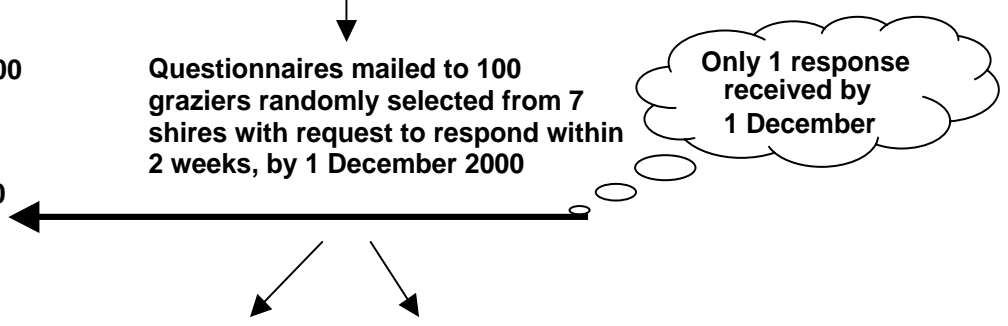

2 radio interviews announcing survey underway and encouraging participation

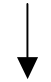

Reminder letter sent out, please complete the survey

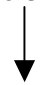

A few graziers phoned to pre-test suitability of surveying non-respondents by phone. Advised we cut number of questions. Decided to survey non-respondents by phone, questions reduced from 121 to 48

25 December 2000

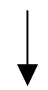

March-April 2001

Non-respondent population surveyed by phone with shorter survey $(n=80)$

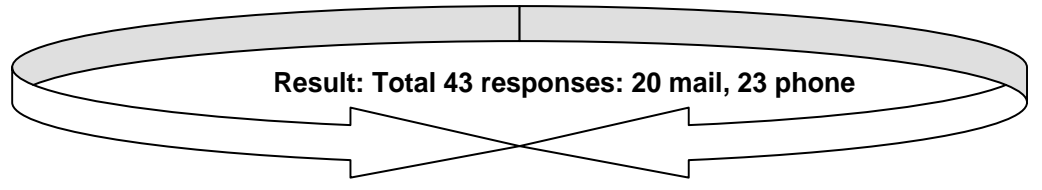

Incentive: All participants were sent a complimentary map of $\mathbf{1 0 0}$ years of monthly Australian rainfall and entered into a draw to win a copy of the Australian Rainman computer software program

Figure 3. Flowchart of survey method. 
Table 2. Sample selection and response rates, by shire

\begin{tabular}{lcccc}
\hline Shire & $\begin{array}{c}\text { Total } \\
\text { population }\end{array}$ & $\begin{array}{c}\text { Number } \\
\text { randomly } \\
\text { selected }\end{array}$ & $\begin{array}{c}\text { Total } \\
\text { responses }\end{array}$ & $\begin{array}{c}\text { Response } \\
\text { rate (\%) }\end{array}$ \\
\hline Aramac & 141 & 16 & 5 & 31 \\
Blackall & 121 & 14 & 5 & 36 \\
Ilfracombe & 54 & 6 & 1 & 17 \\
Longreach & 142 & 16 & 9 & 56 \\
McKinlay & 128 & 16 & 10 & 63 \\
Richmond & 119 & 14 & 4 & 29 \\
Winton & 161 & 18 & 9 & 50 \\
Total & 866 & 100 & 43 & Overall 43\% \\
\hline
\end{tabular}

carry in $80 \%$ of years without needing to destock) and their actual stocking rates, using the 3 categories above. Cross tabulating mail respondents' actual stocking rates with what they consider safe rates for their properties, showed 13 match their estimated safe carrying capacity, 2 stock less than their estimate and 1 stocks more than their estimate.

A chi-square statistical test was undertaken, using the estimated safe carrying capacity from the 16 mail respondents and actual stocking rates of 41 graziers, to see if there were significant differences in the distribution across the 3 stocking rate categories. There was no significant difference $(P=0.80)$, which indicates there is no evidence in this dataset that what graziers consider is safe carrying capacity, is different from what they do in general.

Percentage probability rainfall forecast that may change a decision. Mail respondents indicated that, if given a probability of exceeding median rainfall forecast of at least $68 \%$, on average, they would consider changing a decision $(n=13)$. This finding provides a benchmark for extension and rural development officers on likely uptake and impact of climate-based information and forecasts to decisions.

\section{Comparing questions within the grazier survey}

Trends in use of the SOI and graziers' knowledge of their climate system. Statistical tests showed no significant trend $(P>0.05)$ between use of the SOI and property size, attitude to risk or computer skill; nor was there a trend between how well graziers answered climate test questions and income, attitude to risk or computer skill.

Respondent profile, property size, income. Respondent property size ranged from 488 ha to 233101 ha, an average of 28270 ha (standard deviation 38406 ha). Respondents collectively manage about 1215000 ha $(n=43)$ or $6 \%$ of the total land area in the region, including towns and stock routes (Park et al. 2001). Gross annual turnover, defined as income before expenses, varied from less than $\$ 20000$ to more than $\$ 150000$, with most (84\%) earning greater than $\$ 100000$ $(n=32)$.

Attitude to risk. We found $71 \%$ of graziers $(n=41)$ consider they are conservative or risk averse in their attitude to managing their grazing enterprise.

Stock management, cell grazing, what graziers consider safe carrying capacities. We found most (63\%) mail respondents $(n=16)$ vary their stock numbers according to forage available, last year's pasture growth or the SOI. The balance (37\%) maintain a constant stocking rate. Just over one-third of graziers (36\%) showed interest in assessing the advantages and disadvantages of applying cell grazing $(n=42)$.

About two-thirds $(65.8 \%)$ of graziers $(n=41)$ run a stocking rate at or below $0.8 \mathrm{dse} / \mathrm{ha}$. Stocking rates were calculated by converting respondents' average stock numbers for cattle and sheep to dse, using a ratio of 7 dse to $1 \mathrm{ae}$, then dividing this by total property area. Respondents' stocking rates were grouped into 3 categories: $<0.55 \mathrm{dse} / \mathrm{ha}$ (31.7\%); 0.55-0.8 dse/ha (34.1\%); and $>0.8 \mathrm{dse} / \mathrm{ha} \mathrm{(34.1 \% ).}$

Table 3. Comparison of graziers' and irrigators' scores on comparative climate test questions

Grazier test was conducted in 2000; irrigator test was conducted in 1999

\begin{tabular}{|c|c|c|}
\hline Grazier test question 2000 & Comparative irrigator question 1999 & Signif. \\
\hline $\begin{array}{l}45 \% \text { correctly answered that in a La Niña event sea surface } \\
\text { temperatures are colder than average around the equator in the } \\
\text { eastern Pacific Ocean }(n=42)\end{array}$ & $\begin{array}{l}50 \% \text { correctly answered that in a La Niña event sea surface } \\
\text { temperatures are colder than average around the equator in the } \\
\text { eastern Pacific Ocean }(n=103)\end{array}$ & n.s. \\
\hline $\begin{array}{l}68 \% \text { correctly answered that the SOI is likely to be negative in } \\
\text { an El Niño year }(n=41)\end{array}$ & $\begin{array}{l}91 \% \text { correctly answered that the SOI is likely to be negative in } \\
\text { an El Niño year }(n=127)\end{array}$ & $* *$ \\
\hline $\begin{array}{l}70 \% \text { correctly answered that with a consistently negative SOI } \\
\text { phase in spring (September-November) they would expect } \\
\text { summer pasture growth to be lower than normal }(n=40)\end{array}$ & $\begin{array}{l}76 \% \text { correctly answered that with a consistently negative SOI } \\
\text { phase at the end of autumn summer rainfall would be likely to } \\
\text { decrease }(n=118)\end{array}$ & n.s. \\
\hline $\begin{array}{l}\text { Only } 8 \% \text { correctly answered in western Queensland, El Niño } \\
\text { Southern Oscillation has the largest impact on pasture growth } \\
\text { compared to rainfall }(n=40)\end{array}$ & $\begin{array}{l}64 \% \text { correctly answered they would expect there to be a strong } \\
\text { relationship between May-June SOI phases and the ability to } \\
\text { predict summer streamflow volumes }(n=97)\end{array}$ & n.c. \\
\hline
\end{tabular}

$* P<0.05 ; * * P<0.01 ; * * * P<0.001 ;$ n.s., not significant.

n.c., not comparable. 
Comparing the grazier survey with the irrigator survey

Understanding of climate phenomena and terms. Irrigators tended to score more correctly than graziers on comparative climate test questions related to ENSO and SOI phases (Table 3), however graziers self-rated their knowledge of these terms and concepts higher (Table 4).

Use of the SOI and key decisions. The irrigator study found that, as farm irrigation area increases, there was significantly $(P<0.001)$ higher use of the SOI in property decision making (Keogh et al. 2004), compared with the grazier survey where there was no significant relationship.

Use of the SOI, who farmers consult and key decisions. We found $36 \%$ of respondents $(n=42)$, compared with $29 \%$ of irrigators $(n=174)$, apply the SOI to property decisions (Table 5). Graziers do not consult widely on their key decision, stocking rate, compared with irrigators who do consult widely when deciding cropping area (Table 5). Graziers rated seasonal climate outlook and rainfall probability more highly than irrigators as important factors in their key decision (Table 5). Seasonal climate outlooks are issued before the forecast period, whereas rainfall probabilities usually refer to climatology.

Information needs, access to technology and computer skills. Graziers indicated interest in decision support tools and information to aid climate, pasture growth and stocking rate decisions and irrigators to aid climate and water availability (Table 6). Grazier and irrigator preferences for accessing this information were similar. Access via their own CD software package, downloading from the internet, print and other media were popular; the least preferred methods included group meetings and communication with local extension officers (Table 6).
Ninety percent of mail respondents (graziers) have access to a computer with $\mathrm{CD}$ ROM, $75 \%$ have access to the internet and $70 \%$ use computer packages to aid property management $(n=19-20)$, compared with 68,51 and $46 \%$ respectively of irrigators $(n=169-172)$ (Table 7). There was no significant difference between graziers and irrigators in terms of computer and internet access or use of computer packages in property management. We found most $(95 \%)$ mail respondents $(n=20)$ have a fax and grazier and irrigator self-ratings of computer skill were similar (Table 7).

\section{Discussion}

The formative evaluation study was a useful tool to stimulate new ideas and benchmark the use and understanding of climate technology in grazing management in Western Queensland.

\section{Project planning and activities modified as a result of survey findings}

In considering the findings of the grazier study, the project team has modified several of its activities and planning and it is working towards addressing 7 key areas identified by the study. These are outlined below.

Gaps in knowledge identified by the survey. Survey results showed areas where knowledge of climate information was lacking. For example, most (92\%) respondents did not know the SOI has a greater impact on pasture growth than it does on rainfall for this region, which suggests many of them may not be aware of the potential benefits of pasture growth forecasting. There was little understanding among respondents about the relationship between sea surface temperatures and ENSO. There are

Table 4. Percentage of graziers and irrigators who rated their own level of understanding of climate phenomena and terms as 'no knowledge'

Grazier test was conducted in 2000; irrigator test was conducted in 1999

\begin{tabular}{lccc}
\hline Climate phenomena, term & $\begin{array}{c}\text { Graziers 2000 } \\
(n=39-41)(\%)\end{array}$ & $\begin{array}{c}\text { Irrigators 1999 } \\
(n=163-169)(\%)\end{array}$ & Signif. \\
\hline Probability of exceedance & $29 \%$ & $38 \%$ & n.s. \\
SOI phases & $25 \%$ & $31 \%$ & $* *$ \\
Relationship between SOI and & $25 \%$ & n.a. & n.a. \\
$\quad$ pasture growth in their area & & & \\
Median rainfall & $23 \%$ & $26 \%$ & n.s. \\
Relationship between SOI and rainfall in their area & $23 \%$ & $24 \%$ & $*$ \\
Sea surface temperatures & $17 \%$ & $30 \%$ & $* *$ \\
Seasonal climate forecasting & $17 \%$ & $23 \%$ & $* *$ \\
Apply climate information to & stocking rate $13 \%$ & decisions $17 \%$ & n.a. \\
SOI & $10 \%$ & $15 \%$ & $*$ \\
El Niño & $10 \%$ & $13 \%$ & n.s. \\
La Niña & $10 \%$ & $16 \%$ & n.s. \\
\hline
\end{tabular}

${ }^{A}$ Original grazier knowledge scale: 1, no; 3, some; 5, average; 7, working; and 10, superior; in order to compare to irrigator responses, grazier ratings were converted as follows: $1-2$, no; $3-6$, some; and 7-10, working.

${ }^{\mathrm{B}}$ Irrigator knowledge scale: 1, no; 2, some; and 3, working.

$* P<0.05 ; * * P<0.01 ; * * * P<0.001 ;$ n.s., not significant; n.a., not applicable. 
some indications respondents do not understand the technical terms 'median' and 'probability' and there appears limited knowledge of climate concepts such as the SOI, El Niño, La Niña, the SOI phases, median rainfall, probability of exceedance and the relationship between SOI and rainfall. The project team have published articles in newsletters to improve grazier understanding of these concepts and workshops have been refined to deliver learning outcomes tailored to these specific gaps in knowledge.

Concentrating learning activities on computers and decision support. We found most mail respondents have access to a computer with a CD ROM and more than two-thirds are already using decision support packages, such as accounting programs. More than half the respondents indicated they would find a decision tool useful to help with climate, pasture growth and stock number decisions (and almost one-third may find one useful). Given this and respondent preferences for receiving information via computer packages and the internet, the project team has decided to concentrate its learning activities around these 2 technologies. Graziers are also being informed of decision support packages already available such as DroughtPlan and Australian Rainman. Further development of the DroughtPlan package is planned, to improve the seasonal and daily analysis of pasture growth. A website is also being developed and customised, to provide climate information on rainfall and pasture growth specific to the Western Queensland region.
Focusing extension in areas where interest is high and knowledge is low. Extension activities, such as invited presentations and workshops, are continuing in areas where interest in climate information is high but gaps in knowledge are evident.

Respondents rated workshops low as a preferred method for accessing information and, as a result of this finding, the project is focusing less on delivering whole-day workshops and is now delivering smaller, shorter workshops to graziers by invitation. Personal contact with graziers is still maintained but the need for long workshops is eliminated. The shorter workshops give graziers a better chance of understanding the information, as opposed to longer workshops where too much information is often delivered. Smaller, shorter workshops have also been achieved through property visits or presentations during other workshops.

Designing extension and written communications. Findings that graziers do not prefer workshops and like to access climate and pasture growth information through other mediums, such as the internet, computer software packages and newsletters, caused the project to modify its planning and activities. The original learning outcomes of the project were aimed at delivering workshops and structured group activities, such as field days. The survey results convinced the project team to adjust their activities to better meet the needs of the graziers. As a result, the new learning outcomes

Table 5. Grazier and irrigator use of the SOI in decision-making

Grazier test was conducted in 2000; irrigator test was conducted in 1999

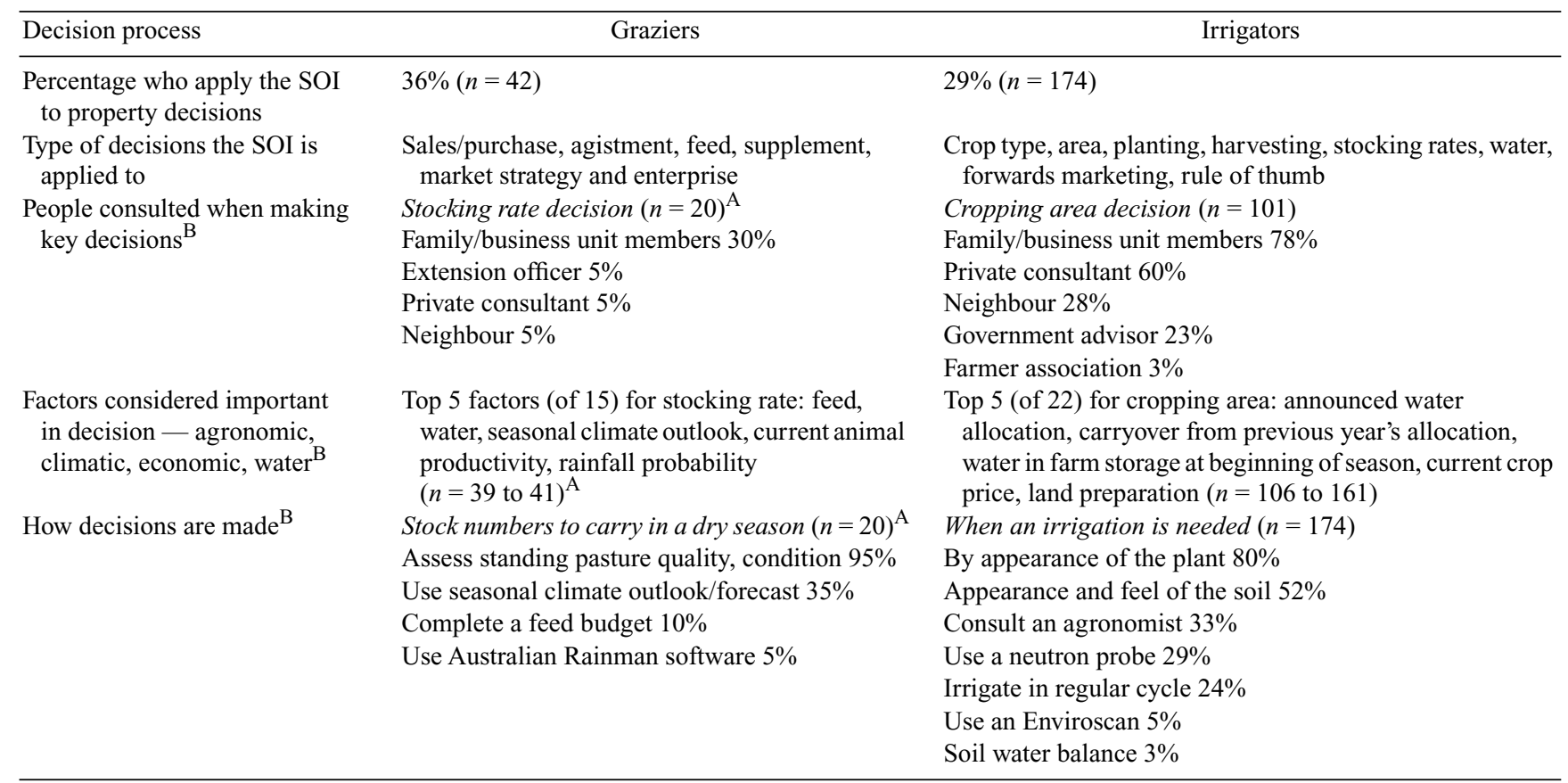

${ }^{\mathrm{A}}$ Mail respondents only $(n=20)$.

${ }^{\mathrm{B}}$ Respondents could select more than one option. 
addition, plans are underway to develop a customised web-page for graziers in Western Queensland.

New learning outcomes are being addressed, particularly with publication of a newsletter entitled 'The Season Ahead'. This quarterly newsletter has been introduced as a result of the survey and began with a mailing list of about 100 . This list has grown to 160 after 3 issues. This newsletter still allows the project team to maintain some personal, one-on-one contact with graziers, without them having to sit through a lengthy workshop. With the newsletter, graziers are not overloaded with information and may achieve a better understanding of climatic issues. The newsletter has contained feature articles and information to address gaps in knowledge, identified by the survey. These include articles on the relationship between pasture growth and rainfall, the impact of the SOI on rainfall and pasture growth, climate change, break-of-season rainfall forecasts and seasonal forecasting in terms of rainfall and pasture growth. Each newsletter issue presents the current seasonal outlook and current phase of the SOI graph, a sea surface temperature map and the current probabilities of exceeding median rainfall and pasture growth. There are also articles outlining the project's current research and results, as well as feature articles from various people involved in specialised work or research covering different climate issues or concepts.

Focusing research on properties with long-term records. Participatory research with graziers is planned, to develop case studies that simulate the long-term value of seasonal climate forecasting on their management of stock.

The project is working with 30 properties that have long-term records, to check and validate simulation model output. The 43 survey respondents are possible new contenders for this participative research activity.

Developing closer contact with the 43 respondents. A bonus from this survey was the opportunity of gaining new clients for the project. The 43 respondents were automatically put onto the mailing list for 'The Season Ahead' newsletter and, in fact, formed the basis of this list. In addition to receiving the newsletter, survey respondents also receive information on any workshops or sessions that are planned for their particular region. It is envisaged that this close contact will continue and it is hoped that, via word-of-mouth, the list of contacts will continue to grow.

Using results of this survey to benchmark the success and impact of this and other projects. This survey is original in that it explores and, to some extent 'tests', grazier levels of understanding of climate phenomena and terms commonly used in climate forecasts in Western Queensland. Results provide a benchmark, against which we can measure the success of this and other similar projects. A further survey is planned at the conclusion of the project. The 'after' survey will determine whether grazier management practices, their knowledge and use of climate concepts and technology has changed as a result of the project and the information emanating from it. It is hoped that the results from the survey will serve as a benchmark for other projects, not only in Western Queensland but in other regions across Australia.

Results are helping the team to better target extension activities to address gaps in clients' knowledge and learning preferences. They have also identified opportunities for research and have introduced 43 potential new clients. Investigating target audience knowledge, practices,

Table 6. Grazier and irrigator information needs

\begin{tabular}{|c|c|c|}
\hline Information needs & Graziers $2000(\%)$ & Irrigators $1999(\%)$ \\
\hline $\begin{array}{l}\text { Percentage who want a tool to aid } \\
\text { decision-making }\end{array}$ & $\begin{array}{l}\text { Climate, pasture growth, stocking } \\
\text { rate decisions }(n=20)^{\mathrm{A}} \\
\text { Yes } 65 \% \\
\text { Maybe } 30 \%\end{array}$ & $\begin{array}{l}\text { Climate, water availability decisions } \\
\quad(n=164) \\
\text { Yes } 57 \% \\
\text { Maybe } 30 \%\end{array}$ \\
\hline Means of accessing information ${ }^{\mathrm{B}}$ & $\begin{array}{l}\text { Preferred } \\
\text { Own CD software package } 44 \% \\
\text { Download from internet } 39 \% \\
\text { Faxback } 39 \% \\
\text { Print media } 33 \% \\
\text { Radio or email } 28 \% \\
\text { Workshop, conference or tv } 22 \% \\
\text { Least preferred } \\
\text { Field days } 16 \% \\
\text { Group meetings } 11 \% \\
\text { Local extension officer } 11 \% \\
\text { Private consultant } 11 \% \\
(n=18)^{\mathrm{A}}\end{array}$ & $\begin{array}{l}\text { Preferred } \\
\text { Faxback } 67 \% \\
\text { Download from internet } 35 \% \\
\text { Media (print, radio, tv) } 30 \% \\
\text { Email } 27 \% \\
\text { Own CD software package } 26 \% \\
\text { Phone-in service } 18 \% \\
\text { Least preferred } \\
\text { Local extension officer } 15 \% \\
\text { Shed meetings } 8 \% \\
(n=143)\end{array}$ \\
\hline
\end{tabular}

${ }_{\mathrm{A}}$ Mail respondents only $(n=20)$.

${ }^{\mathrm{B}}$ Respondents could select more than one option. 
information needs and preferences demonstrates a socially responsible attitude towards intended users of the research and information; and sharing findings may provide a useful guide for colleagues working in similar fields.

Irrigator and grazier comparisons. Estimated gross value of production figures in Queensland for 2000-01 were: beef, $\$ 2.68$ billion; wool, $\$ 186$ million; and cotton, $\$ 489$ million. The numbers of producers were: beef, 19266; wool, 2233; irrigated cotton, 425; and non-irrigated cotton, 176 (Australian Bureau of Statistics 2000). The comparison of survey results for irrigators and graziers suggest that, although they have diametrically opposing enterprise types, there are similarities between the 2 groups. These include rates of access to computers and the internet, use of computer packages, how they rated their personal computing skill, use of the SOI in property decisions and how they prefer to access decision support information.

We found irrigators consult more widely than graziers on their key decision and they self-rated their knowledge of climate phenomena differently. As farm irrigation area increased, irrigator use of the SOI tended to increase, however no similar trend was found among graziers. Both groups indicated a preference for accessing decision support information via computer packages or the internet and were less interested in field days, group meetings and interaction with extension officers. Seasonal climate outlook and probability of rainfall information was more important to graziers, featuring in the top 5 of 15 important factors in their key decision. Irrigators placed more importance on water availability factors.

\section{Comparisons with other studies}

In comparing results with similar studies, we found several similarities and trends.

Survey response rates. Our $43 \%$ sample response rate compares favourably with other mail-out surveys to farmers ranging from 6 to $65 \%$ that used a variety of methods for selecting their population. A mail survey of 2000 randomly selected farmers in the northern, central and southern tablelands of NSW achieved a $6 \%$ response rate (Bayley et al. 1994); others surveyed a whole population, that is, all 931 regulated irrigators in the NSW and Queensland sections of the Northern Murray-Darling Basin received an $18.7 \%$ response rate (Keogh et al. 2000a, 2000b, 2004); and all 2000 farmers in the northern wheat belt of NSW, $20 \%$ response rate (Hayman and Alston 1999). A purposive sample of selected Queensland graziers achieved a $65 \%$ response rate (Paull and Hall 1999).

Similar climate technology studies. Seasonal climate outlook and rainfall probability rated in the top 5 of 15 factors graziers consider important when deciding stocking rate and $35 \%$ of mail respondents use seasonal climate outlook/forecasts to decide stock numbers to carry in a dry season compared with 39\% (Paull and Hall 1999). We found $36 \%$ of graziers use the SOI in decision making compared with $29 \%$ of irrigators and, unlike the irrigator study, we found no trend between grazier use of the SOI and farm area (Keogh et al. 2004). Paull and Hall (1999), in their study of selected Queensland graziers, found $45 \%$ use seasonal climate forecasts, such as information on the SOI, El Niño, Indian Ocean temperatures or other indicators, to assist decisions. A recent survey of over 2500 Australian farmers (including graziers) found $\sim 3$ out of 4 are aware of seasonal forecasts and about two-thirds of sugar and cotton farmers use them in farm management decisions (CLIMAG 2001).

Our study identified gaps in grazier knowledge of climate phenomena and terms but we found no trend between how well they answered climate test questions and income, attitude to risk or computer skill. Almost $25 \%$ of graziers have no knowledge about median rainfall, SOI phases or the relationship between SOI and rainfall in their area, but most $(90 \%)$ had some knowledge or a working knowledge of the terms SOI, El Niño and La Niña. Irrigators performed better than graziers on comparative test questions about ENSO (91 v. 68\%) and SOI phases (76 v. 70\%); however, graziers self-rated their knowledge of these terms and concepts higher. By comparison a mail survey in 1988-89, before release of ENSO-based long-range forecasts in Australia, of

Table 7. Grazier and irrigator access to technology and computer skill

\begin{tabular}{lllc}
\hline Item & Graziers 2000 (\%) & Irrigators 1999 (\%) \\
$(n=19-20)$ & \multicolumn{1}{c}{$\begin{array}{c}\text { Signif. of comparing } \\
\text { surveys }\end{array}$} \\
\hline Have a fax & $95 \%$ & n.a & n.a. \\
Access to computer with CD ROM & $90 \%$ & $68 \%$ & n.s. \\
Internet access & $75 \%$ & $51 \%$ & n.s. \\
Use computer packages to aid property management & $70 \%$ & $46 \%$ & n.s. \\
Self-rated computer skill & Nil 25\% & Nil 31\% & n.a. \\
& Basic 35\% & Basic 36\% & \\
& Intermediate 25\% & Intermediate 27\% & \\
& Advanced 15\% & Advanced 6\% & \\
\hline
\end{tabular}

\footnotetext{
A Mail respondents only. n.s., not significant; n.a., not applicable.
} 
196 mainly cattle and mixed grain producers with an overall response rate of $43 \%$ (Childs et al. 1991) found in their test question $52 \%$ understood El Niño or an ENSO year generally implied decreased rainfall for Queensland; $28 \%$ did not understand what it meant; and the balance thought it meant more rain or something else. Gaps in grazier knowledge have implications for language, content and format design of climate-based information, tools, training and workshop curriculum. Some terms and concepts will require special attention, to help graziers accurately interpret and apply climate-based information.

New research shows that, in relation to modelled growth of Mitchell grass, pasture growth forecasts based on ENSO explains up to $84 \%$ of actual Mitchell grass growth (Park et al. 2003). ENSO also influences temperature, humidity, radiation and evaporation. These, in turn, affect pasture growth and modelled pasture growth as some multiple greater than rainfall (Cobon 1999). We found $92 \%$ of graziers were unaware that ENSO's predictive relationship is greater for pasture growth than rainfall in Western Queensland. Probability-based pasture growth forecasts can provide valuable guides to graziers to anticipate feed requirements, plan stocking rates, agistment and assist other property decisions and low awareness of the phenomena suggests graziers may be currently unaware of their potential value.

Stocking rate is considered one of the most important management decisions graziers make, because of its major impact on long-term resource condition and financial performance (Tothill and Gillies 1992; Gramshaw 1995; Ash and Stafford Smith 1996; Johnston et al. 2000). Cropping area decision is similarly important for irrigators. We found about two-thirds of mail respondents run stock at or below $0.8 \mathrm{dse} / \mathrm{ha}$ and vary stock numbers according to forage available, last year's pasture growth or the SOI. A stocking rate of greater than $0.8 \mathrm{dse} / \mathrm{ha}$ could be considered unsafe for a Mitchell grass system, but this could only be verified using an objective on-property assessment. More than 1 in 3 graziers showed interest in cell grazing and we found little difference in the general trend between what mail respondents consider safe carrying capacity and actual stocking rates of the 41 graziers responding to the survey.

Only about one-third of graziers consult others when deciding stocking rate [compared with $78 \%$ of irrigators who consult family or business members or $60 \%$ who consult private consultants when deciding cropping area $(n=174)]$. Grazier and irrigator preferences for accessing decision support information were similar and included their own CD software package, the internet, fax, print and other media. Group meetings and extension officers were among the least preferred methods. These findings lend some support and validation to software and internet-based information development efforts for this target audience. Interestingly, the Paull and Hall (1999) study of selected Queensland graziers found they preferred to access seasonal climate outlook information via television, rural newspapers and radio, nominating computer packages and internet or email as their least preferred method.

Rates of computer technology uptake. Use of computers by graziers for property management appears to be increasing. Bortolussi et al. (1999) found 52\% of 33 graziers, interviewed in central west Queensland in 1996-97, use a personal computer to aid property management and $22 \%$ use the internet and email. This can be compared with results from 65 selected graziers surveyed in Queensland in 1998 (Paull and Hall 1999), of whom 61\% have a computer, 20\% have access to the internet and $72 \%$ have a fax. Our grazier study in 2000 found $90 \%$ of mail respondents have access to a computer with CD ROM, $75 \%$ have access to the internet, $95 \%$ have a fax and $70 \%$ (compared with $46 \%$ of irrigators, $n=174)$ use computer packages to aid property management.

Care should be exercised in interpreting grazier results related to computer use, due to the sample numbers in the mail sample and the high level of users among that sample. In reviewing comparisons made between the irrigator and grazier surveys, differences in sampling approaches and survey timing need to be borne in mind.

The agricultural implications of the grazier study are that the project has changed its planning, project activities and extension strategy to address knowledge gaps, grazier practices, information needs and preferences identified in the evaluation. The study will be repeated at project-end with this or another random sample, to assess project impact and effectiveness.

\section{Conclusions}

The study has progressed some way towards addressing and exploring what are cited as some of the major hindrances to use of forecasts in decision-making: difficulty interpreting forecasts and limited access to expertise (Changnon et al. 1995; Austen et al. 2002). A snapshot of current grazier knowledge, practice and information needs has also emerged and likely climate technology uptake indicated.

The evaluation proved a useful exercise for the project team and valuable information was gained to improve knowledge transfer, project success and measure impact. The study led to a richer understanding of how well graziers understand climate terms and concepts important for application. It also led to changes in the project's planning and activities. The project is now focusing learning activities and information dissemination around computers, site-specific web technology and newsletters, as well as delivering shorter, smaller workshops, in line with grazier preferences. Extension activities will be focussed where interest is high and knowledge low. Gaps identified in grazier knowledge are being addressed in workshop design and in targeted newsletters. 
Although the project is already working directly with 30 properties, this study has afforded it the opportunity to build working relationships with the 43 respondent graziers. This may help transfer climate technology and information into grazier communities and aid sustainable, profitable decision making. These 43 new contacts are contenders for participatory research, to develop case studies that simulate the long-term value of seasonal climate forecasting for stock and property management. Survey respondents who maintain property records are potentially useful reference sites for scientific modellers and developers who are ground-truthing geospatial and geographic information systems or developing decision support software.

Results of this evaluation study can provide benchmarks for measuring change in practice in regional, state and national land, water, and wool projects, for aspects such as identifying gaps in climate knowledge, use of climate-based information, forecasts and the internet and planning extension activities.

\section{Acknowledgments}

The authors gratefully acknowledge the 43 graziers who participated in this survey, the Natural Heritage Trust and Land and Water Australia, through the 'Climate Variability in Agriculture Program', for their financial support.

\section{References}

Ash AJ, Stafford Smith DM (1996) Evaluating stocking rate impacts in rangelands: animals don't practice what we preach. The Rangeland Journal 18, 216-243.

Australian Bureau of Statistics (2000) 'Agriculture survey. Agricultural commodities produced.' (ABS: Canberra)

Austen EA, Sale PWG, Clark SG, Graetz B (2002) A survey of farmers' attitudes, management strategies and use of weather and seasonal climate forecasts for coping with climate variability in the perennial pasture zone of south-east Australia. Australian Journal of Experimental Agriculture 42, 173-183. doi:10.1071/EA01030

Bayley D, Fairley J, Anderson R, Grant R, Kelleher F, Andrews A (1994) An evaluation of prime pastures. I. In 'Proceedings of the 9th annual conference of the Grassland Society of NSW'. pp. 102-103.

Bortolussi G, Hodgkinson JJ, Holmes CR, McIvor JG, Coffey SG (1999) 'Report on the northern Australian beef industry survey activity central-west region report, June 1999.' CSIRO Division of Tropical Agriculture, Indooroopilly, Qld.

Cane MA (2000) Understanding and predicting the world's climate system. In 'Applications of seasonal climate forecasting in agricultural and natural ecosystems - the Australian experience'. (Eds GL Hammer, N Nicholls, C Mitchell) (Kluwer Academic: The Netherlands) $34 \mathrm{pp}$

Changnon SA, Changnon JM, Changnon D (1995) Uses and applications of climate forecasts for power utilities. Bulletin of the American Meteorological Society 76, 711-720. doi:10.1175/ 1520-0477(1995)0762.0.CO;2

Childs IRW, Hastings PA, Auliciems A (1991) The acceptance of long-range weather forecasts: a question of perception? Australian Meteorological Magazine 39, 105-112.

Clewett JF, Clarkson NM, Owens DT, Abrecht DG (1994) AUSTRALIAN RAINMAN: Rainfall information for better management [a computer software package]. Department of Primary Industries, Brisbane.
Clewett J, Cliffe N, Drosdowsky L, George D, O’Sullivan D, Paull C, Partridge I, Saal R (2000) Building knowledge and skills to use seasonal climate forecasts in property management planning. In 'Applications of seasonal climate forecasting in agricultural and natural ecosystems - the Australian experience'. (Eds GL Hammer, N Nicholls, C Mitchell) (Kluwer Academic: The Netherlands) 304 pp.

Clewett JF, Smith PG, Partridge IJ, George DA, Peacock A (1999) AUSTRALIAN RAINMAN VERSION 3: an integrated package of rainfall information for better management [a computer software package]. Department of Primary Industries, Brisbane.

Cobon DH (1999) Use of seasonal climate forecasts for managing grazing systems in Western Queensland. In 'Proceedings of 6th international rangeland congress'. (Eds D Eldridge, D Freudenberger) pp. 855-857.

Cox PG (1996) Some issues in the design of agricultural decision support systems. Agricultural Systems 52, 355-381. doi:10.1016/ 0308-521X(96)00063-7

CLIMAG (2001) 'Survey shows forecasts use up'. Issue 5, May, p. 4.

Dart J, Petheram RJ, Straw W (1998) 'Review of evaluation in agricultural extension.' (Rural Industries Research and Development Corporation, Barton, ACT)

Gramshaw D (Ed) (1995) 'Integrated management for sustainable forage-based livestock systems in the tropics.' (Department of Primary Industries: Brisbane)

Hayman PT, Alston CL (1999) A survey of farmer practices and attitudes to nitrogen management in the northern New South Wales grains belt. Australian Journal of Experimental Agriculture 39, 51-63. doi:10.1071/EA98120

Johnston P, McKeon G, Buxton R, Cobon D, Day K, Hall W, Scanlan J (2000) Managing climatic variability in Queensland's grazing lands — new approaches. In 'Applications of seasonal climate forecasting in agricultural and natural ecosystems - the Australian experience'. (Eds GL Hammer, N Nicholls, C Mitchell) pp. 197-226. (Kluwer Academic: The Netherlands)

Keogh DU, Abawi GY, Dutta SC, Crane AJ, Ritchie JW, Harris TR, Wright CG (2004) Context evaluation: a profile of irrigator climate knowledge, needs and practices in the northern Murray-Darling Basin to aid development of climate-based decision support tools and information and dissemination of research Australian Journal of Experimental Agriculture 44, 247-257.

Keogh DU, Abawi GY, Dutta SC, Crane AJ, Ritchie JW, Harris TR, Wright CG (2000a) 'Climate knowledge, information needs and practices of irrigators in the northern Murray-Darling Basin: a context evaluation: synopsis of results, August 2000.' Department of Natural Resources, Coorparoo, Qld.

Keogh DU, Abawi GY, Dutta SC, Crane AJ, Ritchie JW, Harris TR, Wright CG (2000b) Can evaluation of irrigator practice, climate knowledge, and information needs lead to development of better decision support tools?: a case study in the Murray-Darling Basin. In 'Proceedings of the 3rd international hydrology and water resources symposium, HYDRO 2000.' Perth. pp. 991-996. (The Institution of Engineers: Perth)

Lynch T, Gregor S, Midmore D (2000) Intelligent support systems in agriculture: how can we do better? Australian Journal of Experimental Agriculture 40, 609-620. doi:10.1071/EA99082

Luukkonen-Gronow T (1987) Scientific research evaluation: a review of methods and various contexts of their application. $R \& D$ Management 17, 207-221.

Martin M, Suzuki A, Kerr D, Easdown W, Chamala S, Bell K (1999) 'Computers on dairy farms in Queensland: a summary report.' Department of Primary Industries, Brisbane. 
McBride JL, Nicholls N (1983) Seasonal relationships between Australian rainfall and the Southern Oscillation. Monthly Weather Review 111, 1998-2004. doi:10.1175/1520-0493(1983)1112.0. $\mathrm{CO} ; 2$

Nicholls N (2000) Opportunities to improve the use of seasonal climate forecasts. In 'Applications of seasonal climate forecasting in agricultural and natural ecosystems - the Australian experience'. (Eds GL Hammer, N Nicholls, C Mitchell) p. 311. (Kluwer Academic: The Netherlands)

Partridge IJ (Ed.) (1994) 'Will it rain? The effects of the Southern Oscillation and El Niño on Australia.' (Department of Primary Industries: Brisbane)

Park JN, Cobon DH, Crabb DM (2001) Integrating climate forecasts and geospatial systems to enhance grazing management in Northern Australia. In 'Proceedings of geospatial information and agriculture conference'. Sydney. pp. 56-70. (Casual Production Pty Ltd: Sydney)

Park JN, Cobon DH, Phelps DG (2003) Modelling pasture growth in the Mitchell grasslands. In 'Proceedings of MODSIM 2003. International congress on modelling and simulation'. Townsville. (Ed. DA Post) pp. 519-524. (Modelling and Simulation Society of Australian and New Zealand Inc.: Canberra)

Paull CJ, Hall W (1999) 'A survey of the assessment of seasonal conditions in pastoral Australia - benchmarking in the Aussie GRASS Project. Part 1: Queensland Report, November 1999.' Queensland Department of Primary Industries, Brisbane.
Pollard V (1992) The education and training needs of farmers. In 'Management for sustainable farming, proceedings of the 16th national conference.' Gatton. pp. 232-241. (The Australian Farm Management Society: Gatton, Qld)

Posavac EJ, Carey RG (1997) 'Program evaluation methods and case studies (5th edn).' (Prentice Hall: New Jersey)

Snedecor GW, Cochran WG (1980) 'Statistical methods (7th edn).' (Iowa State University Press: Ames, IA, USA)

Tothill JC, Gillies C (1992) 'The pasture lands of northern Australia: their condition, productivity and sustainability.' Tropical Grassland Society of Australia, Occasional Publication No. 5.

Troup AJ (1965) The Southern Oscillation. Quarterly Journal of the Royal Meteorological Society 91, 490-506.

Worthen BR, Sanders JR, Fitzpatrick JI (1997) 'Program evaluation: alternative approaches and practical guidelines.' (Longman: New York, NY, USA)

Received 17 December 2001, accepted 23 August 2002 